Aksaray University
Journal of Science and Engineering
e-ISSN: 2587-1277
http://dergipark.gov.tr/asujse
http://asujse.aksaray.edu.tr

Research Article

\title{
Investigation of Changes in Noise Levels of Boron Carbide Doped Circular Saws in Granite Cutting
}

\author{
Gokhan Ekincioglu ${ }^{1, *}$, Rasit Altindag ${ }^{2}$ \\ ${ }^{1}$ Kırşehir Ahi Evran University, Kaman Vocational School, Drilling Technology, Kırşehir, Turkey \\ ${ }^{2}$ Süleyman Demirel University, Faculty of Engineering, Department of Mining Engineering, Isparta, Turkey

-Received Date: May 14, $2019 \quad$-Revised Date: Sep 12, $2019 \quad$ •Accepted Date: Sep 17, $2019 \quad$ Published Online: Dec 14, $2019 \quad$

\begin{abstract}
Noise is an important physical risk factor in natural stone processing plants as in many other industries. For this reason, determination of the noise level occurring in natural stone cutting processes is important in terms of worker health and safety. Natural stone cutting operations are carried out by circular saws with diamond socket. In addition to the rock properties and cutting parameters, the diameter of the saw body and the structure of the sockets affect the noise intensity during cutting. In this study, a boron carbide non-doped $\left(0 \% \mathrm{~B}_{4} \mathrm{C}\right)$ saw and 7 different ratios $\left(1,2,3,4,5,6,7 \% \mathrm{~B}_{4} \mathrm{C}\right)$ boron carbide doped circular saws have been produced. Changes in noise levels during cutting experiments performed with boron carbide doped circular saws were examined in terms of worker health and safety. As a result of the data obtained, it was determined that the noise level produced by circular saw with $1 \% \mathrm{~B}_{4} \mathrm{C}$ was the lowest. The circular saw with $1 \% \mathrm{~B}_{4} \mathrm{C}$ is thought to contribute to the natural stone sector in terms of worker health.
\end{abstract}

\section{Keywords}

Natural stone, Circular saw, Boron Carbide, Noise

*Corresponding Author: Gokhan Ekincioglu, gekincioglu@ahievran.edu.tr 


Aksaray University
Journal of Science and Engineering
e-ISSN: 2587-1277
http://dergipark.gov.tr/asujse
http://asujse.aksaray.edu.tr

Research Article

\title{
Granit Kesme İşleminde Bor Karbür Katkılı Dairesel Testerelerin Gürültü Değerlerindeki Değişimlerinin İncelenmesi
}

\author{
Gökhan Ekincioğlü,1, Raşit Altında $\breve{g ̆}^{2}$ \\ ${ }^{1}$ Kırşehir Ahi Evran Üniversitesi, Kaman Meslek Yüksekokulu, Sondaj Teknolojisi, Kırşehir, Türkiye \\ ${ }^{2}$ Süleyman Demirel Üniversitesi, Mühendislik Fakültesi, Maden Mühendisliği Bölümü, Isparta, Türkiye \\ •Gönderi Tarihi: 14 May $2019 \quad$ •Düzeltme Tarihi: 12 Eyl $2019 \quad$-Kabul Tarihi: 17 Eyl $2019 \quad$ •Çevrimiçi Yayln Tarih:14 Ara 2019
}

\section{Özet}

Gürültü birçok diğer endüstri kolunda olduğu gibi doğal taş işleme tesislerinde de önemli bir fiziksel risk etmenidir. $\mathrm{Bu}$ nedenle doğal taş kesme işlemlerinde ortaya çıkan gürültü düzeyinin belirlenmesi işçi sağlığı ve güvenliği açısından önemli olmaktadır. Doğal taş kesme işlemleri, elmas soketli dairesel testereler ile gerçekleştirilmektedir. Kesimde kullanılan kayaç özellikleri ve kesme parametreleri yanı sıra testerenin çapı, gövde kalınlığı ve soket yapısı kesim sırasında oluşan gürültü şiddetini etkilemektedir. Bu çalışma kapsamında bir adedi bor karbür katkısız $\left(\% 0 \mathrm{~B}_{4} \mathrm{C}\right)$ referans testere olmak üzere 7 farklı oranda $\left(\% 1,2,3,4,5,6,7 \mathrm{~B}_{4} \mathrm{C}\right)$ bor karbür katkılı dairesel testere üretilmiştir. Üretilen bor karbür katkılı dairesel testereler ile gerçekleştirilen kesme deneyleri esnasında ortaya çıkan gürültü değerlerindeki değişimler işçi sağlığ 1 ve iş güvenliği kapsamında incelenmiştir. Elde edilen veriler sonucunda \% $1 \mathrm{~B}_{4} \mathrm{C}$ katkılı dairesel testerenin ortaya çıkarmış olduğu gürültü seviyesinin en düşük olduğu belirlenmiş olup koruyucu elemanların kullanılması ile doğal taş sektörüne işçi sağlı̆̆ı açısından ayrıca bir katkısı olacağı düşünülmektedir.

\section{Anahtar Kelimeler}

Doğal taş, Dairesel testere, Bor Karbür, Gürültü

\footnotetext{
"Sorumlu Yazar: Gökhan Ekincioğlu, gekincioglu@ ahievran.edu.tr
} 


\section{GIRİŞ}

Gelişen teknoloji ile birlikte dünyada ve ülkemizde hızlı bir artış göstermekte olan sanayileşmenin ve makineleşmenin, insan faktörüyle birleşmesi birçok sağlık ve güvenlik riskinde artış meydana getirmektedir. Çalışanlar yaptıkları işe ilişkin çok farklı risk etmenleriyle karşı karşıya kalmaktadırlar [1]. İş yerinin fiziki şartları; aydınlatma, gürültü, titreşim, hava koşulları, toz, gaz ve buhar gibi unsurlar fiziksel risk etmenlerini ortaya çıkarmaktadır. Ortaya çıkan bu fiziksel risk etmenleri iş güvenliği, işçi sağlığ 1 , üretkenlik ve iş kalitesini direkt olarak etkilemektedir [2].

Sanayileşme ve modern teknolojinin ilerlemesiyle iş sağllğ 1 ve iş verimini etkileyen önemli çevre sorunlarından biri de gürültü kirliliğidir. Gürültü, çalışanların geçici ve kalıcı duyma kayıplarına neden olmasının yanı sıra yorgunluktan sırt ağrılarına, sinirlilikten bulantı ve dikkatsizliğe kadar çok değişik şekillerde etkilemektedir [3-5]. İşitme kaybı ilk bakışta gürültüye bağlı ortaya çıkan bir meslek hastalığı olduğu kadar, iş kazalarının nedenleri içerisinde önemli bir yer oluşturmaktadır. Gürültünün frekansı, ortamdaki bulunma süresi, gürültünün noktasal, düzlemsel veya çizgisel kaynaktan kaynaklanmış olup olmadığı, gürültüye maruz kalan kişinin yaşı, fiziki ve ruhsal durumu, gürültünün bulunduğu ortamda zamana göre dağılımı gibi durumlar gürültünün alıcı tarafından rahatsızlık olarak algılanmasında önemli olan etkenlerdendir [5-6].

Madenciliğin ülke ekonomisindeki yeri önemli olmakla beraber madenlerde çalışan işçilerinin çalışma koşullarının iş sağlığı ve güvenliği açısından iyileştirilmesi de bir o kadar öneme sahip bir konudur. Bu durum gürültü açısından ele alındığında, gürültü kontrolüne yönelik devamlı ve etkin mücadele stratejilerinin daha sağlıklı, verimli bir çalışma ortamının oluşturulmasına katkı sağlayacağı açıktır [7]. Maden işçileri genel olarak maden işletme, cevher hazırlama ve zenginleştirme işlemleri olmak üzere tüm üretim süreçlerinde gürültüye maruz kalmaktadır. $\mathrm{Bu}$ maruziyet durumu yüksek gürültü seviyeleri ile doğal taş sektöründe de karşımıza çıkmaktadır. Mermer ocaklarından çıkarılan mermer blokları, mermer işleme fabrikalarında inşaat sektöründe binaların iç ve dış kaplamalarında ve yer döşemelerinde çeşitli ebatlarda kullanılmak üzere elmas uçlu lamalar ve elmaslı dairesel testereler ile kesilmektedir [5]. Testere ve kayaç arasında oluşan titreşimler testerenin taşa uyguladığı kuvvetler sonucunda, testere gövdesinde ve taşta oluşan titreşimlerin yarattığı şok ses dalgaları havada gürültü olarak yayılır. Oluşan gürültünün şiddeti testere tasarımına (gövdede kullanılan çeliğin özellikleri, gövde kalınlığı, testere çapı, soket geometrisi ve sayısı, su kanalları arasındaki genişlik) kesilen taşa 
(sertlik, mineralojik özellikler vb.) ve çalışma parametrelerine (kesme hızı, ilerleme hızı, kesme derinliği, çevresel hız ve soğutma suyu miktarı) bağlıdır [8]. Literatürde bu konu ile ilgili yapılan çalışmaların özetleri aşağıda verilmiştir.

Ucun vd. 2 farklı kayaç türü için kesme deneyleri gerçekleştirmişlerdir [9]. Her iki kayaç türü için kesme kuvvetleri, güç tüketimi, özgül enerji ve gürültü değerlerini belirlemişlerdir. Ucun vd. mermer kesme işleminde bor yağı katkılı soğutma sıvısının disk performansı üzerindeki etkisini incelemişlerdir [10]. Bor yağının kesme kuvvetleri, güç tüketimi, soket aşınması ve kesme sırasında çıkan gürültü üzerine etkisini araştırmışlardır. Bor yağı oranının artmasına bağlı olarak, yukarıda belirtilen parametrelerde belirli oranda azalmanın olduğunu belirlemişlerdir. Bor yağının fazla kullanılması durumunda ise mermer yüzeyine talaş sıvanmasını arttırdığını ve mermer yüzey görünümünü nispeten bozduğunu gözlemlemişlerdir. Şengün vd. [5] çeşitli mermer işleme fabrikalarında oluşan gürültü düzeylerini belirlemiş ve sınır değerlerle karşılaştırmalarını yapmışlardır. Çalışma sonunda mermer işleme fabrikalarındaki gürültü düzeyinin sürekli çalışma için izin verilen sınır değerlerden yüksek olduğunu belirlemişlerdir. Bayram vd. [11] ticari ismi Afyon Beyaz olan hakiki mermer üzerinde farklı çevresel hızlarda ve farklı ilerleme hızlarında kesme deneyleri gerçekleştirmişler ve kesimde oluşan gürültü seviyesinin kesme parametreleriyle ilişkilerini incelemişlerdir. Çalışma sonunda ölçülen gürültü seviyelerinin kesme kuvveti, birim aşınma ve birim enerji değerleriyle ilişkili olduğunu tespit etmişlerdir.

Şengün vd. [12] 10 farklı kayaç üzerinde gerçekleştirmiş oldukları kesme deneylerinde testerenin boştaki ve yükteki durumuna göre gürültü seviyesi ölçümleri ile testere devir ölçümlerini gerçekleştirmişlerdir. Kayaçların fiziksel, mekanik özellikleri ve kesme deneylerinde belirlenen özgül kesme enerjisi değerlerinin, testere devri ve gürültü değerleri ile arasındaki ilişkileri istatistiksel olarak incelemişlerdir. Bir mermer işleme tesisinde gürültü değerlerinin ortalama 85-95 dB aralığında olduğunu belirlemişlerdir. Bu nedenle dayanımı ve sertliği yüksek kayaçların kesimleri sırasında ilave iş güvenliği ve işçi sağlığı önlemlerinin arttırılmasının önemini vurgulamışlardır. Yılmaz, Güneş [13] sandviç-çekirdek testere ve geleneksel testere olmak üzere iki farklı testerenin güç tüketimi, kuvvet oranı, özgül aşınma oranı ve gürültü seviyesi üzerine etkilerini Blue Pearl granit numunesinde gerçekleştirilen kesme deneyleri ile incelemiştir. Çalışma sonucunda sandviç- çekirdek testerenin diğerine göre güç tüketiminin ve özgül aşınma miktarının daha az olmasının yanı sıra sandviç çekirdekli testerenin ortalama ses düzeyinin geleneksel testereye göre yaklaşı $10 \mathrm{~dB}$ daha düşük olduğunu belirlemiştir. 
Günümüzde çok genel mesleki hastalıklardan birisi de aşırı gürültü nedeniyle oluşan işitme kaybıdır. $\mathrm{Bu}$ nedenle mermer kesme ve işleme fabrikalarında kesim esnasında dairesel testerelerin ortaya çıkarmış olduğu gürültünün azaltılması için çalışmalar yapılmaktadır [14]. $\mathrm{Bu}$ çalışma kapsamında da bor karbür katkılı soketlerin sabit kesme koşullarında (testere ilerleme hızı, çevresel hız, kesme derinliği, su miktarı, kullanılan taş türü) gerçekleştirilen kesme işlemleri esnasında oluşan gürültü değerleri üzerine etkisi incelenmiştir.

\section{MATERYAL VE METOT}

Granit en sert doğal taşlardan birisi olup, atmosferik şartlara karşı gösterdiği direnç ve estetik görünüme sahip olması nedeni ile zemin ve duvar kaplamasının yanı sıra mutfak tezgâhları gibi yapı sektöründe birçok alanda kullanılmaktadır [14].

$\mathrm{Bu}$ çalışma kapsamında bor karbür katkılı soketler ile gerçekleştirilen kesme işlemleri esnasında ortaya çıkan gürültünün kayaç kesilebilirlik parametresi olmasının yanı sıra işçi sağlığ1 ve iş güvenliği açısından da değerlendirilmesi amaçlanmıştır. Bu amaçla öncelikle çalışmada kullanılacak granit türü ve bor karbür temini gerçekleştirilmiştir. Temin edilen kayacın kimyasal, mineralojik-petrografik, fiziksel ve mekanik özellikleri dikkate alınarak kayaç yapısına uygun olarak aynı sinterleme şartları altında farklı oranlarda bor karbür katkısı gerçekleştirilmiş ve dairesel testereler üretilmiştir. Bor karbür katkılı dairesel testere üretimi sonrasında aynı kesme şartları altında kesme deneyleri gerçekleştirilmiş olup bor karbür katkısının kesim sırasında oluşan gürültü değerleri üzerindeki değişimler incelenmiştir.

\subsection{Bor Karbür}

Bor karbür, dünyada yüzlerce bor kimyasalı arasında yüksek pazar hacmine sahip önemli bir bor uç ürünüdür [15]. Bor karbür, fiziksel özelliklerine bağlı olarak testereler gibi seramikler ve sert çalışma malzemelerinin işlenmesinde kullanılmaktadır [16].

Metalik bağlayıcının aşınma direncini arttırmak ve elmas ile bağlayıcı ara yüzeyindeki bağı güçlendirmek amacı ile bağlayıcıya karbürler ilave edilmektedir. Son zamanlarda yüksek ergime noktası, yüksek sertliği, düşük yoğunluğu, yüksek kimyasal kararlılık ve mükemmel mekanik özelliklere sahip bor karbür ileri teknoloji için önemli bir malzemedir. Bor karbür elmas ve kübik bor nitrürden sonra bilinen en sert malzemedir. Yüksek sertliğinden dolayı aşınma direncinin iyileştirilmesi amacıyla kullanılmaktadır. [17-19].

Çalışma kapsamında da soket bağlayıcısına takviye elamanı olarak bor karbür kullanılmış olup bor karbürün kesilebilirlik parametreleri yanı sıra kesim sırasında oluşan gürültü üzerine etkisi incelenmiştir. Tablo 1'de Elmas soketlerde kullanılan bor karbürün kimyasal içeriği verilmiştir. 
Tablo 1. Bor karbür kimyasal içeriği [14]

\begin{tabular}{|c|c|c|c|c|c|}
\hline Element & $\mathbf{B}$ & $\mathbf{C}$ & $\mathbf{O}$ & $\mathbf{F e}$ & $\mathbf{S i}$ \\
\hline$\%$ & $75-77$ & $18-21$ & $0.1 *$ & $0.15-0.25^{*}$ & $0.1^{*}$ \\
\hline
\end{tabular}

\subsection{Bor Karbür Katkısız ve Katkılı Elmas Soket ve Dairesel Testere Üretimi}

Çalışma kapsamında ticari ismi Hisar Gri olan ve mineralojik olarak kuvars-monzonit bileşimindeki kayacın fiziksel ve mekanik özellikleri belirlenmiştir. Elde edilen veriler Tablo 2’de verilmiştir.

Tablo 2. Hisar Gri kayacının fiziksel ve mekanik özellikleri [14]

\begin{tabular}{|c|c|c|c|}
\hline & Minimum & Ortalama & Maksimum \\
\hline Özgül Ağırlık & 2.689 & 2.697 & 2.701 \\
\hline Birim Hacim Ağırlık (gr/cm³) & 2.613 & 2.622 & 2.632 \\
\hline Ağrılıkça Su Emme (\%) & 0.399 & 0.424 & 0.435 \\
\hline Hacimce Su Emme (\%) & 1.048 & 1.112 & 1.167 \\
\hline Toplam Porozite (\%) & 2.380 & 2.784 & 3.030 \\
\hline Böhme Yüzey Aşınma $\left(\mathrm{cm}^{3} / 50 \mathrm{~cm}^{2}\right)$ & 7.601 & 7.640 & 7.677 \\
\hline Tek Eksenli Basınç Dayanımı (MPa) & 174.78 & 206.63 & 237.07 \\
\hline Nokta Yükü Dayanım Endeksi (MPa) & 7.10 & 7.97 & 9.36 \\
\hline Brazilian Çekme Dayanımı (MPa) & 8.13 & 9.85 & 10.54 \\
\hline Knopp Sertlik & 315.65 & 445.82 & 622.12 \\
\hline Shore Sertlik & 79.5 & 90.8 & 98.2 \\
\hline
\end{tabular}

Belirlenen kayaç özelliklerine göre NERGİS Elmas Teknolojileri şirketi tarafindan bir adedi bor karbür katkısız $\left(\% 0 \mathrm{~B}_{4} \mathrm{C}\right)$ referans testere olmak üzere 7 farklı oranda $(\% 1,2,3,4,5,6,7$ $\mathrm{B}_{4} \mathrm{C}$ ) granit kesimine uygun $350 \mathrm{~mm}$ çapında bor karbür katkısız ve katkılı 8 adet dairesel testere üretimi gerçekleştirilmiştir. Soketler endüstriyel ortamda $35 \mathrm{MPa}$ basınç altında $730{ }^{0} \mathrm{C}$ sıcaklıkta ve 3 dakika sinterleme süresinde üretilmiştir. Bor karbür katkılı elmas soketli dairesel testerelerin görünümü Şekil 1'de verilmiştir.

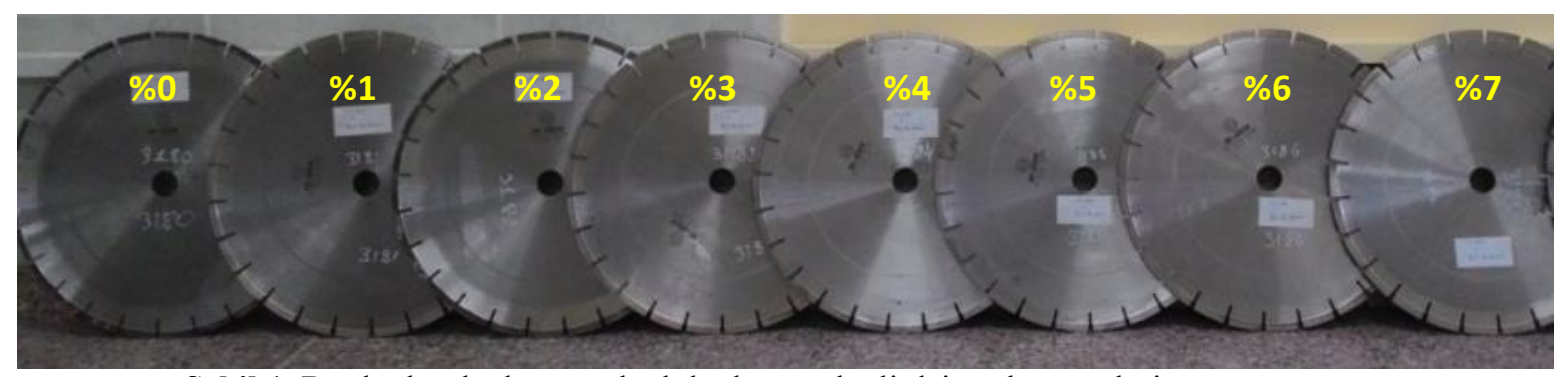

Şekil 1. Bor karbür katkısız ve katkılı elmas soketli dairesel testerelerin görünümü.

\subsection{Kesme Deneyleri}

Çalışma kapsamında bor karbür katkılı ve katkısız dairesel testereler ile gerçekleştirilen kesme deneyleri sonucunda her bir testerenin kesim sırasında ortaya çıkarmış olduğu gürültü değerleri belirlenmiştir. 
Kesme deneyleri Süleyman Demirel Üniversitesi, Maden Mühendisliği Bölümü, Doğal Taş Teknolojisi Laboratuvarında bulunan kesme setinde gerçekleştirilmiştir. Şekil 2'de kesme deney seti elemanlarının genel görünümü verilmiştir.

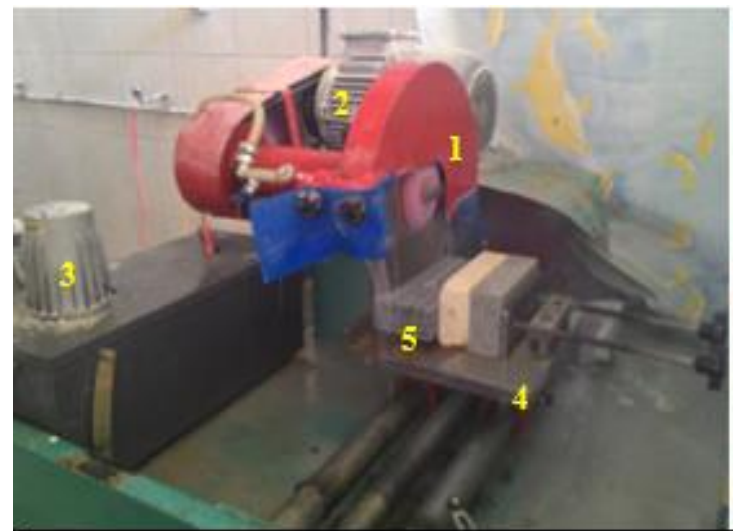

1. Testere

2. Testere motoru

3. Soğutma suyu pompası

4. Vagon

5. Numune

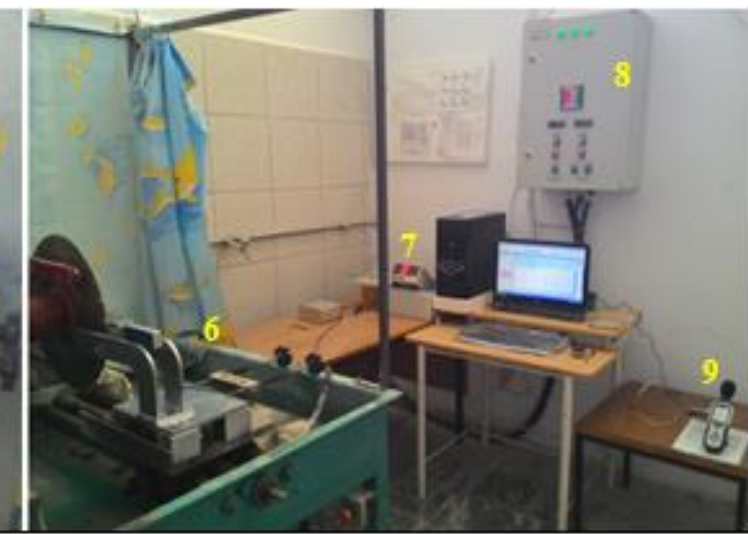

6. Aşınma ölçüm sistemi

7. Enerji analizörü

8. Elektrik panosu

9. Gürülttï ölçer

Şekil 2. Kesme deney seti elemanlarının genel görünümü

Çalışmada biri bor karbür katkısız 7, adedi farklı orandaki bor karbür katkılı (\%0, 1, 2, 3, 4, 5, 6, $7 \mathrm{~B}_{4}$ C) 8 adet dairesel testerenin kesim sirasında oluşturdukları gürültü değerlerinin belirlenmesi amacı ile kesme deneyleri gerçekleştirilmiştir. Kesme deneylerinde de tek bir doğal taş türü kullanılmış olup testere çevresel hızı, ilerleme hızı, kesme derinliği ve su miktarı gibi kesme parametreleri sabit tutulmuştur. Çalışma öncesinde kesme deney seti ve kesimi gerçekleştirilen kayaç yapısı dikkate alınarak farklı varyasyon deneyleri gerçekleştirilmiş olup elde edilen verilere göre optimum kesme parametreleri (testere çevresel hızı, ilerleme hızı, kesme derinliği, su miktarı) belirlenmiştir. Daha sonrasında da kesme deneyleri gerçekleştirilmiştir. Tablo 3 'te çalışmada sabit tutulan kesme parametreleri verilmiştir.

Tablo 3. Kesme işlemlerinde sabit tutulan kesme parametreleri

\begin{tabular}{cccc}
\hline $\begin{array}{c}\text { Çevresel hız } \\
\left(\mathbf{V}_{\mathfrak{c}}, \mathbf{m} / \mathbf{s}\right)\end{array}$ & $\begin{array}{c}\text { Kesme derinliği } \\
\left(\mathbf{h}_{\mathbf{k}}, \mathbf{m m}\right)\end{array}$ & $\begin{array}{c}\text { İlerleme hız } \\
\left(\mathbf{V}_{\mathbf{i}}, \mathbf{m} / \mathbf{d k}\right)\end{array}$ & $\begin{array}{c}\text { Özgül taşıma oranı } \\
\left(\mathbf{Q}_{\text {net }}, \mathbf{c m}^{2} / \mathbf{d k}\right)\end{array}$ \\
\hline 30 & 10 & 0.7 & 70 \\
\hline
\end{tabular}

Deneylerde, doğal taş sektöründe yaygın olarak kullanılan aşağı-yönlü kesme yöntemi seçilmiştir. Kesme deneyleri öncesinde aşındırıcı özellikte beton bloklar ile testerelerin bilenmesi sağlanmıştır. Deneylerde soğutma suyu miktarının etkisini ortadan kaldırmak için ortama sabit miktarda 10 lt/dk olarak harici bir pompa yardımıyla soğutma suyu verilmiştir. Kesme deneylerinde her bir blok numunede 12 adet kesim yapılmıştır. Her bir testere için 5 
adet blok numune üzerinde 60 kesim toplamda 8 testere için 480 adet kesim gerçekleştirilmiştir. Kesme deneyleri sonrasında 5x10x25 cm ebatlarındaki blok numunelerinin görünümü Şekil 3’te verilmiştir.

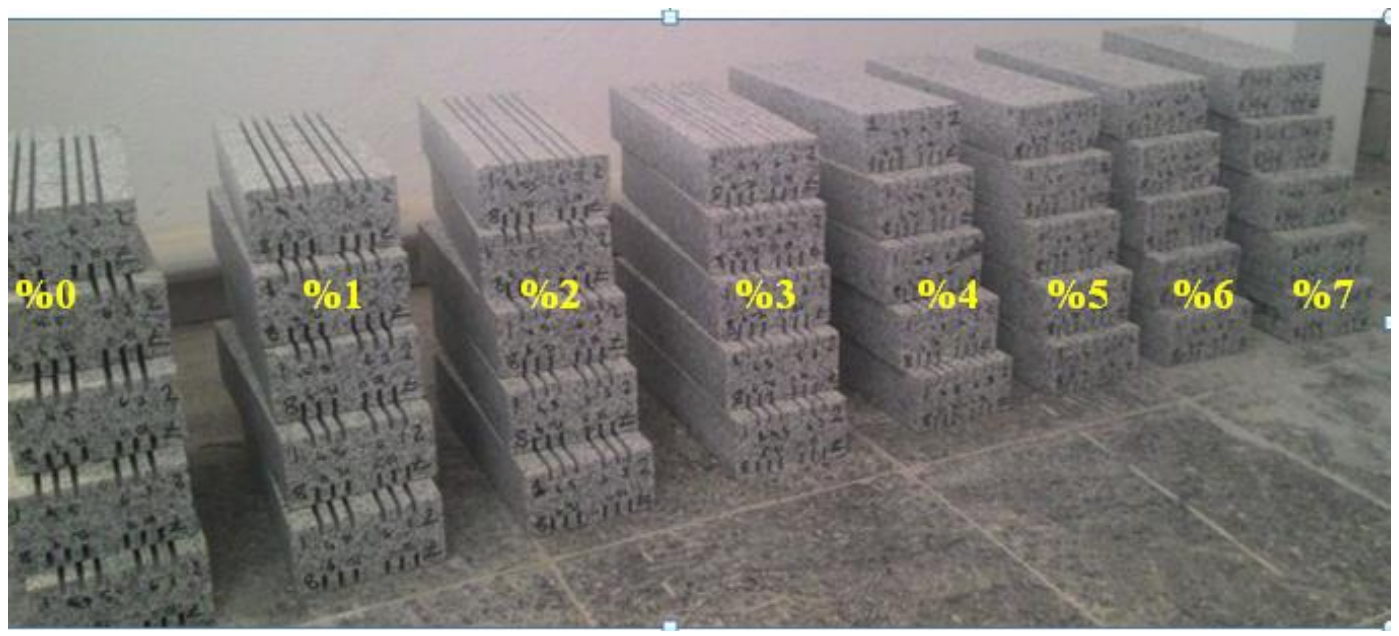

Şekil 3. Kesme deneyi sonrası Hisar Gri blok numunelerinin görünümü.

\subsection{Gürültü Seviyesi Ölçümü}

Gürültünün şiddetini ölçen cihazlara gürültü ölçer veya ses ölçer denilmektedir. Gürültü seviyesi ölçüm cihazları; herhangi bir andaki ses yüksekliğini ölçmek için kullanılmaktadır. Ölçümler gürültü kaynağında yapılarak iş makinesinin ya da çalışan ekipmanın ortama yaydığı gürültü miktarı tespit edilmektedir [7]. Bu cihazlar gürültünün şiddetini desibel (dB) olarak gösterir. $\mathrm{Bu}$ cihazlar gürültü değerlerini $\mathrm{dB}(\mathrm{A})$ ve $\mathrm{dB}(\mathrm{C})$ olarak ölçebilmektedir. Desibel, ölçülen bir değerin seçilen bir referans değerine olan oranının logaritması olup, ölçeksiz bir birimdir. Referans değer olarak, insan kulağının işitebileceği en düşük ses şiddeti $0 \mathrm{~dB}$, en yüksek ise $140 \mathrm{~dB}$ kabul edilmektedir [8].

Çalışma kapsamında gerçekleştirilen kayaç kesme işlemleri esnasında CEM DT-8852 model gürültü ölçüm cihazı kullanılmış olup Tablo 4’te teknik özellikleri verilmiştir (Şekil 4).

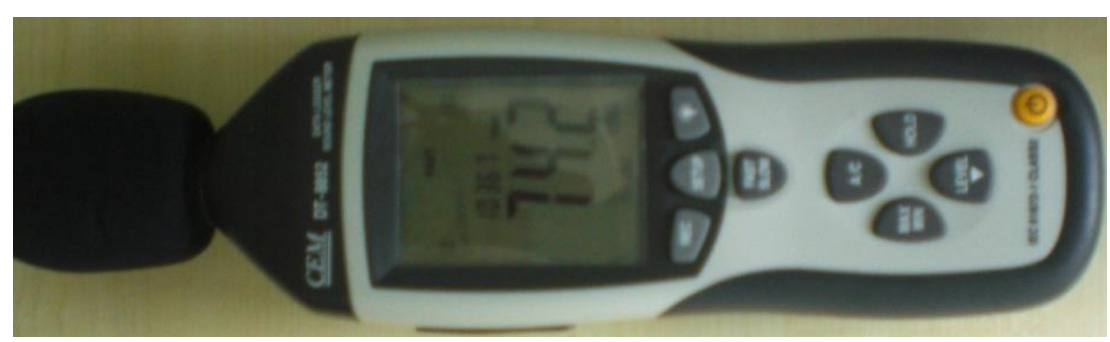

Şekil 4. Gürültü ölçer görünümü

Tablo 4. Gürültü ölçüm cihazına ait teknik özellikler

\begin{tabular}{lc}
\hline \multicolumn{1}{c}{ Tanım } & Değer \\
\hline Frekans aralığı & $31.5 \mathrm{~Hz}-8 \mathrm{kHz}$ \\
Doğruluk & $\pm 1.4 \mathrm{~dB}$ \\
Otomatik ölçüm aralığı & $30-130 \mathrm{~dB}$ \\
Çözünürlük & $0.1 \mathrm{~dB}$ \\
\hline
\end{tabular}


Kayaç kesme işlemleri sırasında çalışma için özel olarak yazılan kesme programının ara yüzü ile gürültü ölçerden alınan verilerin bilgisayar ekranından grafiklerle izlenebilmesi sağlanmıştır (Şekil 5).

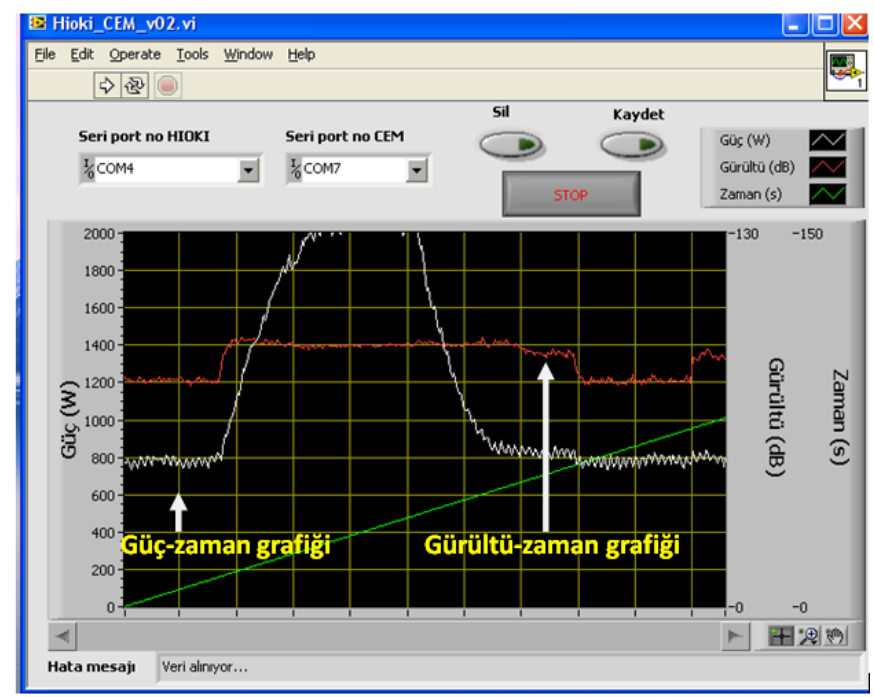

Şekil 5. Kesme programı ara yüz görünümü.

Program ile saniyede 5 adet veri alınmış olup TXT dosyası olarak kaydedilmiştir. Kesim sonrasında da TXT dosyaları Excel ortamında açılarak her bir testerenin oluşturduğu gürültü değerleri hesaplanmıştır. Şekil 6'da \%4 $\mathrm{B}_{4} \mathrm{C}$ katkılı testereye ait gürültü seviyesi-kesim süresi verilmiştir.

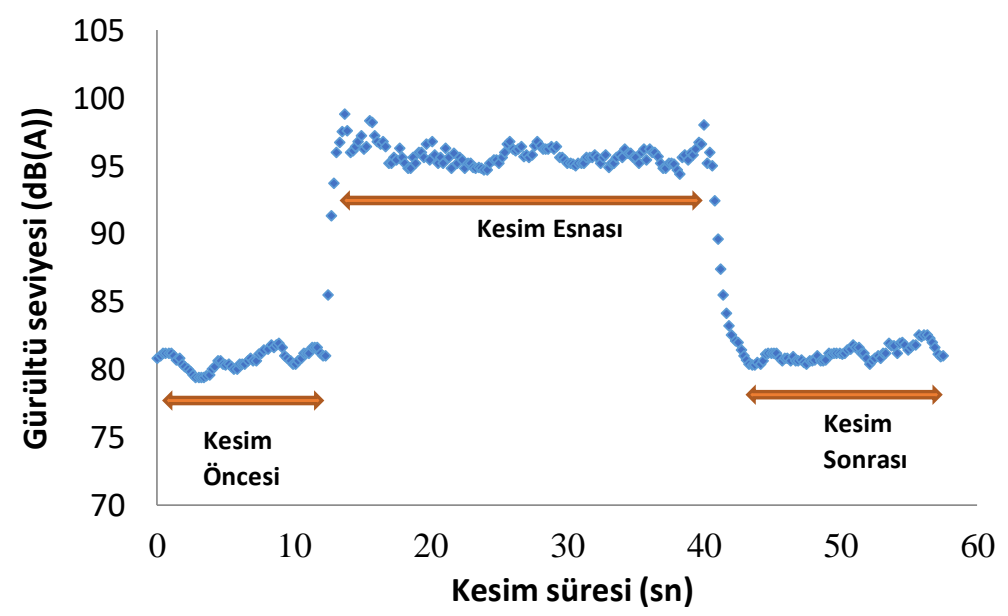

Şekil 6. \% $4 \mathrm{~B}_{4} \mathrm{C}$ katkılı testereye ait gürültü seviyesi-kesim süresi grafiği.

\section{BULGULAR VE TARTIŞMA}

Doğal taş kesme işlemlerinde ortaya çıkan gürültü dairesel testerelerde bir kesim parametresi olmakla birlikte işçi sağlığı ve güvenliği açısından da önemli olmaktadır. $\mathrm{Bu}$ çalışma kapsamında üretilen bor karbür katkılı dairesel testereler ile gerçekleştirilen kesme deneyleri sonrasında kesim sırasında oluşan gürültü değerlerindeki değişimler belirlenmiştir. 


\subsection{Gürültüi Seviyesi Değerleri}

Çalışma kapsamında gerçekleştirilen kesme deneyleri sonucunda kesim esnası sırasında elde edilen gürültü seviyesi değerlerinin aritmetik ortalamaları Tablo 5 'te verilmiştir.

Tablo 5. Bor karbür oranına bağlı gürültü seviyesi değerleri.

\begin{tabular}{cccccc}
\hline \multirow{2}{*}{$\mathbf{B}_{\mathbf{4}} \mathbf{C}$} & \multicolumn{5}{c}{ Gürültü seviyesi (dB) } \\
\cline { 2 - 6 } & Kesim sayısı & Minimum & Ortalama & Maksimum & Standart sapma \\
\hline 0 & 60 & 96.33 & 96.98 & 97.79 & 0.31 \\
1 & 60 & 91.53 & 92.81 & 93.66 & 0.71 \\
2 & 60 & 92.17 & 93.02 & 93.74 & 0.21 \\
3 & 60 & 92.85 & 93.96 & 94.70 & 0.41 \\
4 & 60 & 95.75 & 96.25 & 96.99 & 0.34 \\
5 & 60 & 95.28 & 95.65 & 95.96 & 0.29 \\
6 & 60 & 94.32 & 94.98 & 96.51 & 0.53 \\
7 & 60 & 93.05 & 93.69 & 95.55 & 0.50 \\
\hline
\end{tabular}

En yüksek gürültü değerleri birbirlerine yakın değer olmakla beraber bor karbür katkısız (\%0) ve \%4 bor karbür katkılı elmas soketlerde olduğu görülmüştür. En düşük değer ise \%1 bor karbür katkılı soketlerde elde edilmiş olup bor karbür katkısız soketlere göre \%4.30 oranında bir gürültü azalmasının olduğu belirlenmiştir. Gürültü üzerindeki bu değişimlerin soket gözenekliliği ve sertliği gibi metalografik özelliklerindeki farklılıklardan kaynaklandı̆̆ düşünülmektedir. Şekil 7'de bor karbür katkı oranına göre gürültü değerlerinin değişimi verilmiştir.

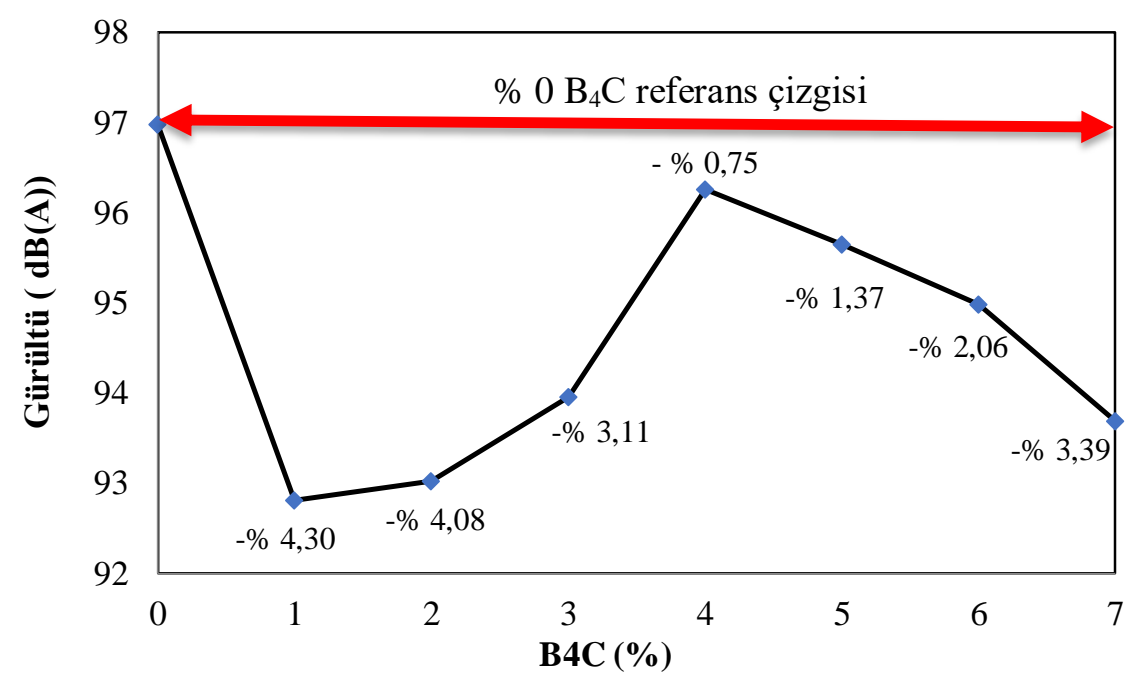

Şekil 7. Bor karbür katkı oranına göre gürültü seviyesindeki yüzdelik değişim.

Ülkemizde var olan gürültü yönetmeliğine göre; sekiz saatlik iş günü için, anlık gürültünün de dâhil olduğu en yüksek maruziyet sınır değeri 87 dB(A) olarak belirlenmiştir [20]. Şekil 8'de 
gürültü maruziyet sınır değere göre bor karbür katkılı testerelerin gürültü değerleri karşılaştırması verilmiştir. Gürültü maruziyet değeri ile karşılaştırıldığında tüm testerelerin sınır değer üzerinde olduğu tespit edilmiştir. Nispeten de olsa \%1 $\mathrm{B}_{4} \mathrm{C}$ katkılı testerenin diğer testerelere göre daha az gürültü ortaya çıkardığg belirlenmiştir. Ancak elde edilen değerler yine de yasal mevzuatta belirtilen en yüksek maruziyet sınır değerini aşmaktadır.

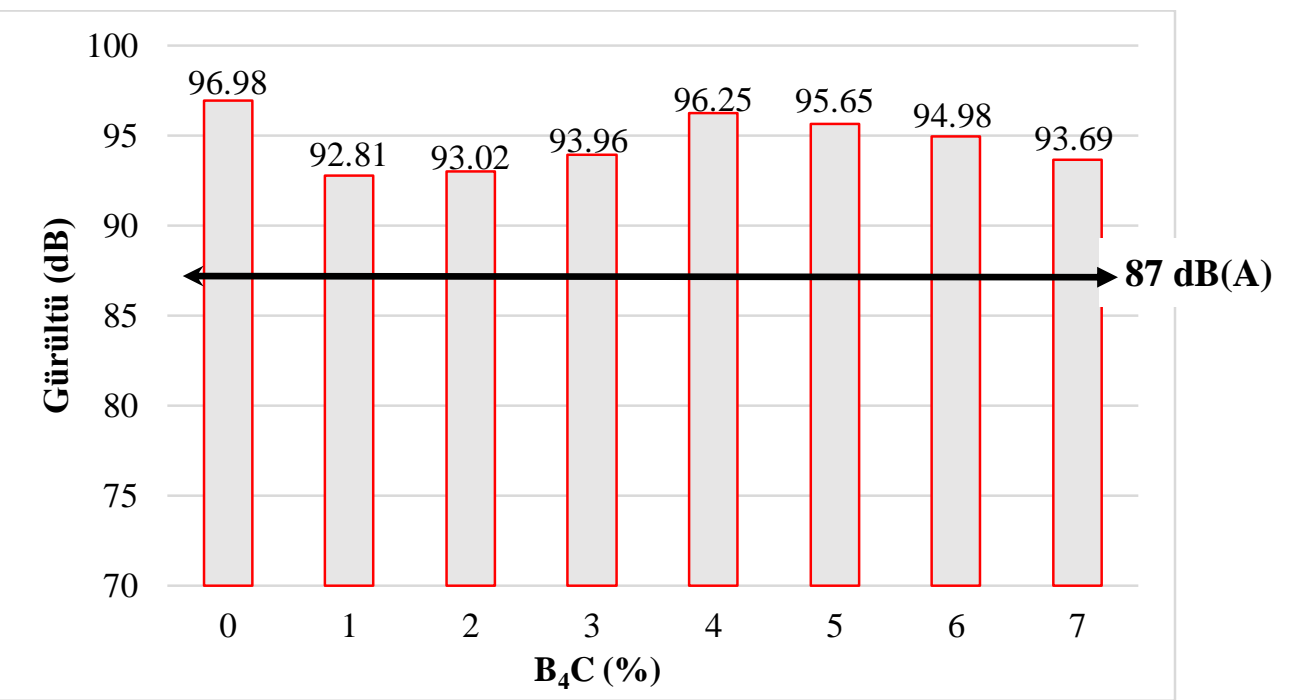

Şekil 8. Gürültü maruziyet sınır değere göre bor karbür katkılı testerelerin gürültü değerlerinin karşılaştırması.

\section{SONUÇLAR}

Gürültü birçok endüstri kolunda olduğu gibi doğal taş işleme tesislerinde de önemli bir risk faktörüdür. Bu nedenle doğal taş kesme işlemlerinde ortaya çıkan gürültünün belirlenmesi işçi sağlığg ve güvenliği açısından önemli olmaktadır.

Gerçekleştirilen çalışma sonucunda referans $\left(0 \% \mathrm{~B}_{4} \mathrm{C}\right)$ ve bor karbür katkılı dairesel testerelerin granit kesimi esnasında oluşturmuş oldukları gürültü seviyesinin sürekli çalışma durumunda çalışanların sağlıklarını bozabilecek üst sınırı olan $87 \mathrm{~dB}(\mathrm{~A})$ değerini aştığı görülmüştür. Gürültü yönetmeliğine göre; "En Yüksek Maruziyet Etkin Değeri” olan 85 dB(A)'den sonra mutlaka işveren kişisel koruyucu donanımların işçiler tarafından kullanılmasını sağlamalıdır. “En Yüksek Maruziyet Sınır Değeri” olan 87 dB(A) ise hiçbir koşulda aşılmaması gereken değerdir.

En yüksek gürültü değeri referans testerede (96.98 dB(A)) elde edilmiştir. Diğer testereler ile karşılaştırıldığında \% $1 \mathrm{~B}_{4} \mathrm{C}$ katkılı dairesel testerenin ortaya çıkarmış olduğu gürültü değerinin (92.81 dB(A)) en düşük olduğu belirlenmiştir. Kulak tıkaçları ve kulaklıklar gibi kişisel koruyucuların kullanımı ile gürültüyü tamamen ortadan kaldırmasa da gürültü düzeyini 8-30 dB değerleri arasında azalttığından dolayı işçi sağlı̆̆ı ve güvenliği açısından doğabilecek 
olumsuz etkileri azaltacaktır. İşçi sağlığı açısından \%1 $\mathrm{B}_{4} \mathrm{C}$ katkılı testerelerin koruyucu elemanların kullanılması ile doğal taş sektörüne katkısı olacağ1 düşünülmektedir.

$\mathrm{Bu}$ çalışma sonucunda soket yapısının kesim esnasında oluşan gürültü değerlerini etkilediği belirlenmiş olup soket üreticilerinin ve bu konu üzerinde çalışan bilim insanlarının soket matriksi üzerine gerçekleştireceği çalışmalar ile kesme verimliliği de göz önünde bulundurularak daha az gürültü ortaya çıkaran soketlerin üretilebileceği düşünülmektedir.

\section{Teşekkür}

Yazarlar, 3100-D2-12 no'lu bilimsel araştırma projesi ile desteklenen bu çalışmadan dolayı Süleyman Demirel Üniversitesi BAP birimine ve bor karbür katkılı dairesel testerelerin üretiminde verdiği destekten dolayı Nergis Nek firmasına teşekkür ederler.

\section{KAYNAKLAR}

[1] T.H. Taştan, Granit fabrikalarında gürültü maruziyetinin değerlendirilmesi. T.C. Çalışma ve Sosyal Güvenlik Bakanlığı İş Sağlığı Ve Güvenliği Genel Müdürlüğü İş Sağlığ1 ve Güvenliği Uzmanlık Tezi, 71 s., Ankara (2016)

[2] H. Serin, Y. Şahin, M. Durgun, Küçük ölçekli mobilya işletmelerinde gürültü analizi. Ormanc1lık Dergisi 9(2) (2013) 1-8.

[3] A. Aybek, S. Arslan, Bazı tarıma dayalı sanayi kuruluşlarında gürültü düzeyleri. KSÜ Fen ve Mühendislik Dergisi, 8(2) (2005)121-127.

[4] H.Ç. Ekerbiçer, A. Saltık, Endüstriyel gürülttünün insan sağlığı üzerine etkileri ve korunma yöntemler. TAF Prev. Med. Bull., 7(3) (2008) 261-264.

[5] N. Şengün, R. Altındağ, S. Demirdağ, ,C.E. Koççaz, Mermer işleme fabrikalarında oluşan gürültü kirliliğinin işçi să̆lı̆̆ ve ilgili mevzuat açısından değerlendirilmesi. İTÜ 12. Endüstriyel Kirlenme Kontrolü Sempozyumu, İstanbul (2010) 427-432.

[6] M.T. Gönüllü, Gürültü kontrolü ders notları, Yıldız Teknik Üniversitesi, (1993) İstanbul.

[7] İ. Çınar, C. Şensöğüt, Mermer hazırlama tesislerinde oluşan gürültünün işçiler üzerindeki maruziyet değerlerinin belirlenmesi. Maden İşletmelerinde İşçi Sağlığı ve İş güvenliği Sempozyumu, (2015) 335-343, Adana.

[8] N. Yılmaz, Magmatik kökenli doğal taşların elmas soketli dairesel testerelerle kesilebilirlik analizleri. Eskişehir Osmangazi Üniversitesi Fen Bilimleri Enstitüsü Doktora Tezi (2009) 209s, Eskişehir.

[9] I. Ucun, K. Aslantaş, S. Taşgetiren, İ.S, Büyüksağiş, Fracture path prediction of diamond segment in a marble cutting disc. Fatigue And Fracture Of Engineering Materials, 31 (2008) 517-525. 
[10] İ.Ucun, İ. S. Büyüksağiş, Elmas soketler aşınmasının belirlenmesinde lazer ölçüm sisteminin kullanılması. 5. Uluslararası İleri Teknolojiler Sempozyumu (2009) Karabük.

[11] F. Bayram, N.E. Yaşıtlı, Y. Özçelik, Dairesel testereli kesimde gürültü seviyesinin kesim parametreleriyle ilişkileri. Türkiye 22. Uluslararası Madencilik Kongresi ve Sergisi Bildiriler Kitab1, (2011) 407-413.

[12] N. Şengün, R. Altındağ, S. Demirdağ, Dairesel testerelerle kesme işleminde testere devir sayısının ve gürültü seviyesi değişimlerinin incelenmesi, Pamukkale Üniversitesi Mühendislik Bilimleri Dergisi, 19(3) (2013)121-126.

[13] N. Yılmaz Güneş, Process efficieny comparison of a sandwich-coresawblade and a conventional saw blade used in stone-machining, Journal of Cleaner Production. 47 (2013) 26-31.

[14] G. Ekincioğlu, Doğal taş kesme işleminde bor karbür katkulı elmas soketlerin kesilebilirlik parametreleri üzerine etkilerinin araştırılmast. Süleyman Demirel Üniversitesi Fen Bilimleri Enstitüsü Doktora Tezi, (2017)157s, Isparta.

[15] E. Alp, E. Karaçay, H.C. Cabbar, Düşük sıcaklıkta bor karbür üretimi ve karakterizasyonu. Gazi Üniv. Müh. Mim. Fak. Der. 28(2), (2013) 293-302.

[16] E. Karaçay, Bor karbür üretimi ve karakterizasyonu. Gazi Üniversitesi Fen Bilimleri Enstitüsü, Yüksek Lisans Tezi, (2008)101s. Ankara.

[17] H.O. Pierson, Handbook of refractorycarbides and nitrides. William Andrew Pub., (1996) Noyes.

[18] Q.C. Ma, G.J. Zhang, Y.M. Kan, Y.B. Xia, P. L. Wang, Effect of addives introduced by ball milling on sintering behavior and mechanical properties of hot-pressed $B_{4} C$ ceremics. Ceramics International, 36 (2010)167-171.

[19] S. Islak, D. Kır, E. Çelik, H. Çelik, Effect of boron carbide on the micro structure and the mechanical properties of segments produced using hot pressing method. Scientific Research and Essays, 7(23) (2012) 2095-2103.

[20] Anonim, Çalışanların Gürültü Ille Illgili Risklerden Korunmalarına Dair Yönetmelik. Resmi Gazete, 28 Temmuz, Sayı 28721 (2013) Ankara. 